\title{
SOCIAL MEDIA USE TO ENABLE BETTER RESEARCH VISIBILITY
}

\author{
Irina Cojocaru ${ }^{1}$ and Igor Cojocaru ${ }^{2}$
}

DOI: $10.24989 /$ ocg.338.35

\begin{abstract}
Research visibility is a synthetic characteristic, defining the level of dissemination, accessibility, recognition and impact of the scientific output of a community. It has been influenced tremendously by the rapid development of ICT and took full advantage of the plethora of ICT tools. The paradigm of Open Science has organically emerged during the last years, advocating for extending the principles of openness to the whole research cycle, fostering sharing and collaboration as early as possible. The use of various ICT-based tools enables the entire research cycle-from literature search and review, reference management, research data processing, publication and peer-review to dissemination of results and outreach within the global academic community. The availability of various customisable online services for researchers, especially social media, contributes significantly to the increase of their presence and visibility in the scientific communities at national, regional and global levels. This paper aims to present an overview of the possibilities afforded to researchers by social media and social networking, its benefits and potential drawbacks, as well as its implications for the future of scholarly communication and research evaluation, the reasons and motivations why researchers are engaging in social media or not.
\end{abstract}

\section{Introduction}

Some of the traditional scholarly communication means are not very supportive of the researcher in sharing their findings, and the end user in taking in this knowledge. This automatically delays the potential for research to influence practice and policy. Citations usually fail to capture the impact of the research on the wider knowledge transfer to the consumer who needs it most. Societal or realworld influence is inherently difficult to assess [16]. To maximize research impact, traditional academic communication channels and researchers should embrace digital technology, and the opportunities it affords. The availability of various customisable online services for researchers, especially social media, contributes significantly to the increase of their presence and visibility in the scientific communities at national, regional and global levels.

These new tools and techniques complement the traditional article format by including blog posts, interactive graphics and videos, informal scholarly conversations move to Twitter, networking, collaboration and career development happen on ResearchGate, LinkedIn or Facebook. The adoption of techniques to generate engagement and impact will inevitably have a learning curve, with some tools proving more beneficial than others. Some of the benefits of using social media in academia, include promoting research and increasing its visibility, building networks, reaching new audiences (both within and outside academia), sharing information and keeping up-date with the latest news and

\footnotetext{
${ }^{1}$ Information Society Development Institute, 5A Academiei str., Chisinau, Republic of Moldova \& State University of Moldova, 60 Alexei Mateevici str., Chisinau, Republic of Moldova, irina.cojocaru@idsi.md

${ }^{2}$ Information Society Development Institute, 5A Academiei str., Chisinau, Republic of Moldova, igor.cojocaru@idsi.md
} 
developments [28]. Some argue that a transition from 'publish or perish' to 'get visible or vanish' is inevitable in the academic world. [4]

This paper aims to present an overview of the possibilities afforded to researchers by social media and social networking, based mainly on literature review. It explores benefits and potential drawbacks of social media, as well as its implications for the future of scholarly communication and research evaluation, the reasons and motivations why researchers are engaging in social media or not.

\section{Research visibility}

Research visibility is a synthetic characteristic, defining the level of dissemination, accessibility, recognition and impact of the scientific output of a community. It has been influenced tremendously by the rapid development of ICT and took full advantage of the plethora of ICT tools.

The exponential growth of the scientific literature during the last decades makes it particularly complicated for researchers to produce publications, that will be noticed by the community - be visible - and generate a scientific, social, economic or other types of impact. No database can cover this huge volume of scientific output. The use of various ICT-based tools facilitates a wide variety of tasks from searching for relevant scientific information, processing research data, publishing scientific papers, reviewing them, and then disseminating and promoting them within the global academic community. Thus, the existence of personalized web services for the needs of the researchers, contributes significantly to the increase of their presence and visibility in the scientific communities at national, regional and global level.

At the same time, visibility is one of the important aspects, which is taken into account in the evaluation process, whether it is of individual researchers, research groups, institutions or even national R\&D systems. Figure 1 shows four important dimensions of research evaluation (including, for example, citation analysis). These issues are highly interrelated and interdependent. Research evaluation should be conducted in particular to determine the strengths and weaknesses of productivity, visibility, reputation and impact of researchers or scientific organizations.

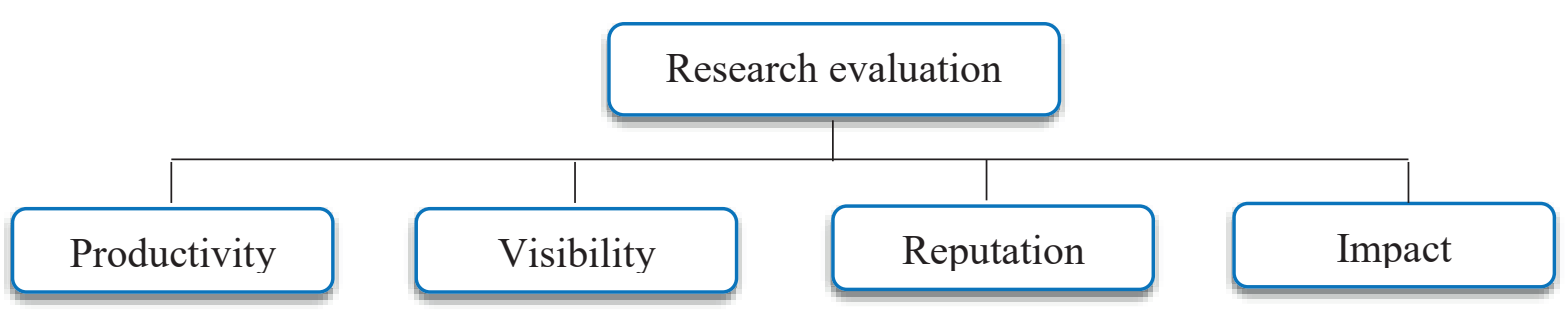

Figure 1: Dimensions of research evaluation

Source: [23]

Visibility in the pre-internet era referred mainly to indicators, such as the number of books sold, the impact of journals or publications depending on the place of publication of an article or presentations at prestigious conferences with high participation. Visibility also referred to references in newspapers, radio or $\mathrm{TV}$, although these were not typical for ordinary researchers. On the other hand, the web offers visibility and the ability to overcome the boundaries of traditional scholarly communication.

Web 2.0, or the social web, offers the means to generate metrics relevant to estimating the scientific reputation, based on the behavior of users online. It refers to social bookmarks (social tagging), 
recommendations, microblogging, references written by users, blogs, social networks, repositories of scientific data. All these methods are based on web users to view, tag, comment, download, share or store scientific results on the web, and the indicators regarding these activities can be generated in real time. Potential benefits relate to faster feedback and a broader assessment of the impact on the public. However, this "public" may not be a valid or authoritative one. In terms of webometric analysis, reputation, recognition and prestige are closely correlated. These refer to the number or rank of sites that mention the scientific activity of a researcher. Although the total number of links or mentions indicates the level of visibility or accessibility of a scientific output, recognition by recognized researchers and prestigious institutions is still a measure of scientific value [22].

\section{Open Science paradigm}

Currently there is a systemic change in the modus operandi of science and research affecting the whole research cycle and its stakeholders and that is Open Science (OS). Being driven by new technologies and data, the increasing demand in society to address the societal challenges of our times and the readiness of citizens to participate in research, this is a new approach to how scientific research is conducted and organized, it is based on cooperation and new ways of knowledge dissemination using digital technologies and new collaborative tools [19]. The paradigm of Open Science has emerged during the last years, advocating for extending the principles of openness to the whole research cycle, fostering sharing and collaboration as early as possible. The use of various ICTbased tools enables the entire research cycle - from literature search and review, reference management, research data processing, publication and peer-review to dissemination of results and outreach within the global academic community.

Being adopted as one of the 3 strategic priorities of the European Commission in 2015, in September 2017, the G7 Ministers recognized that technological and societal developments are transforming research towards paradigms of Open Science. They stressed the importance of incentivising and rewarding Open Science activities and providing global research infrastructures, to underpin it [10]. One of the key dimensions of Open Science is Open Evaluation. In an Open Evaluation environment, there are written peer reviews, bibliographies, numerical ratings, usage statistics, social web information and citations in combination with other usage or participatory elements from social media. The altmetrics movement is currently developing a range of novel indicators to assess impact [17].

"Altmetrics" is used as an umbrella term which condenses ideas on how to combine social media with aspects of traditional scholarly practice (Priem et al., 2010) and is considered a subset of webometrics, although using new data sources and methods. The aim of altmetrics is to expand our views on impact, by considering new data sources and metrics. Altmetrics considers all stages and products of scholarly research (from "social" literature search via Facebook to discussion of published results with readers via Twitter), including any impact a publication or an author may have on other people, e.g., retweeting a tweet, downloading or bookmarking an article, sharing a blog post in social networks, or following the author. As such, the altmetrics approach offers new ways to measure impact of authors and publications which may complement rather than replace traditional indicators for research evaluation [3]. The combination of traditional and alternative metrics for research evaluation will provide more complete author or article profiles as it captures more dimensions of scientific practice.

Open Science (OS) is a term that mainly evokes a deep change in the scientific environment on both knowledge creation and dissemination towards a public funded science to be more open, accessible, global, transparent, integral, reliable, collaborative, and closer to citizens. This is inherently good for the quality of science and for improving the efficiency of the R\&I systems [19]. Open science has the 
potential to increase the quality and benefits of science, bringing significant opportunities such as increased visibility and transferability of scientific knowledge.

\section{Social media in academia: reasons and motivations for engagement}

Recently, both scientists and science communicators have issued numerous calls to the scientific community to engage in social media to both connect with other scientists (inreach) and to connect with the public (outreach) [15]. The benefits of social media stem from active participation and the generation of new attractive content from an individual. Research is about producing new information and knowledge and social media offers unique opportunities to present new content. As of December 2019 there were about 7.8 billion people in the world, of which 3.725 billion were active social media users. Moreover, there are almost 1 mil new users to some form of social media every day or a new user every 10 seconds [26].

Social media are user-centred internet-based tools that foster online collaboration, sharing, communication, participation and creation of user-generated content [14]. Categories of social media services include social networking (e.g., Facebook, LinkedIn), microblogging (e.g., Twitter), blogging, photo sharing (e.g., Instagram, Pinterest), video sharing (e.g., YouTube), and crowdsourcing. Social network sites are defined as web based services that allow individuals to (1) construct a public or semi-public profile within a bounded system, (2) articulate a list of other users with whom they share a connection, and (3) view and traverse their list of connections and those made by others within the system [5].

Scholars are increasingly incorporating social media into their scholarly practice. Increasing pressure on researchers by funding agencies, organisations and universities to engage in the broader social field and demonstrate societal impact has led scholars to turn to online environments to produce, consume and disseminate information. This has in turn enabled the incorporation of online activities into scientific evaluations [8]. Besides maintaining existing connections and making new ones, researchers use social media to increase their visibility and that of their work as well as to expand the reach of events, such as conferences, meetings and workshops.

Citation counts are established in author evaluation, but they reflect only half the truth: they just capture the author's impact on other authors, while the impact on pure readers is missed. Moreover, authors create "footprints" via profiles in social networks, homepages, or publication lists to make themselves and their work more visible. These aspects of scholarly behavior are also not acknowledged by citation counts. With social media, new platforms come into play which provide alternatives to gain a holistic view on the visibility and impact of authors [3].

Researcher profiles are strategic and selective "digital representations" [18] of researchers and their research. As stated by Cheek \& Øby (2019), the increasing display and use of altmetrics has lead to an increasing proliferation of online guides about how to establish a high-profile online presence or researcher self, aiming to improve the online visibility of the researcher and of his or her research put another way, by making these "much more googleable" [6].

The reasons of engaging in social media are quite diverse, according to Jaring \& Back (2017): some of the researchers had started to use social media out of social pressure from peers, some out of curiosity, and some because they were involved in projects that required being present in social media. The majority of researchers use social media to find information and stay up-to-date with the latest developments, as well as share their findings [13]. Sharing findings leads to the end user in taking in 
new knowledge. Otherwise the potential for research to influence practice and policy is significantly delayed (e.g. it takes 17 years for just $14 \%$ of medical research to be implemented into everyday practice [12]). To maximize research impact, journals and researchers should embrace digital technology and the opportunities it affords.

This could also help ensure that more scientists would enjoy the professional benefits of social media use. Although, it has yet to be widely adopted, still the scientists in a variety of disciplines use these platforms to exchange scientific knowledge, generally via either Twitter, Facebook, LinkedIn or blogs, perceiving numerous potential advantages to using social media in the workplace [7].

Among these, Twitter has emerged as a key outlet. The brevity of 'tweets', and the capacity to include images and videos, means that scientists can go through a lot of information at a glance, with the option to dig deeper if they wish. The constant stream of posts can be filtered to match the user's interests through the creation of lists. Live-tweeting from conferences has become common and offers many benefits, such as allowing attendees and non-attendees alike to receive messages about talks and participate in discussions [27]. According to a critical evaluation of science outreach via social media by McClain \& Neeley (2014), there also appears to be an overall positive correlation between the number of citations and number of Twitter followers among scientists [15].

The recent study by French \& Fagan (2019) suggests that faculty with more academic social network profiles were more visible in search engines and faculty with authority records (such as ORCID) ranked more highly in Google. Therefore, it is no surprise that increasing numbers of academic publishers and funders are requiring authors to use identifiers such as ORCID, and librarians are incorporating the topic of identity management into their outreach to faculty. A variety of academic social networks (ASN) are available to researchers for creating and managing their online scholarly identities: Academia, Google Scholar, ResearchGate, ORCID etc. [9]. Table 1 presents a brief overview of these 4 ASNs. 


\begin{tabular}{|l|l|}
\hline ORCID & $\begin{array}{l}\text { ORCID is a nonprofit organization dedicated to ensuring that "all who } \\
\text { participate in research, scholarship and innovation are uniquely identified and } \\
\text { connected to their contributions and affiliations" [20]. It is primarily an } \\
\text { identifier system that also provides a web platform where researchers can link } \\
\text { their publications to their ORCID and enter profile information. }\end{array}$ \\
\hline Google Scholar & $\begin{array}{l}\text { Google Scholar is the most familiar and most used ASN site, according to a } \\
\text { 2014 Nature survey [29]. The platform presents itself primarily as a search } \\
\text { engine for scholarly articles with an added profile feature. Google Scholar } \\
\text { provides links to publications on a variety of commercial, open access, and } \\
\text { personal websites, provided the content is scholarly in nature and includes an } \\
\text { abstract or full text [11]. }\end{array}$ \\
\hline Academia.edu & $\begin{array}{l}\text { Academia describes itself as "a platform for academics to share research } \\
\text { papers" and its mission is "to make every scholarly and scientific paper } \\
\text { available for free on the internet and to enhance academic discussion and } \\
\text { collaboration" [2]. Users can create a profile, upload their work, and use social } \\
\text { networking features to connect with other researchers. }\end{array}$ \\
\hline ResearchGate & $\begin{array}{l}\text { ResearchGate's mission is "to connect the world of science and make research } \\
\text { open to all," and the for-profit company describes itself as "the professional } \\
\text { network for scientists and researchers" [24]. The Innovations in Scholarly } \\
\text { Communication global survey found that ResearchGate was used by twice as } \\
\text { many published scholars as Academia. }\end{array}$ \\
\hline
\end{tabular}

Table 1: Overview of academic social networks

Source: [9]

\section{Benefits vs drawbacks of social media for research}

Social media is seen as a good source of new information and contacts, and it is suitable for promoting awareness of research services and results. The results of a recent study on social media use by researchers by Jaring \& Back (2017) show that the speed and intensity of social media present challenges for researchers, but by being active in posting content and participating in discussions, researchers can derive benefits and enhance their personal reputations.

Researchers presumably report benefitting from using social media in different ways [13]:

- $\quad$ gaining professional visibility and credibility;

- networking: it is easier to go to talk to people or call them when you are following them on social media;

- $\quad$ event information: finding out about interesting events and following events if participating was not possible;

- $\quad$ finding information about project calls, projects, new trends and ideas;

- $\quad$ following professionally relevant news anywhere and anytime through mobile;

- $\quad$ gaining an idea of someone's personality by following their social media activities.

Despite the professional benefits of social media, many scientists are reluctant to use them for work. Developing a useful digital footprint is time-consuming and many scientists struggle to fit this into their already heavy schedules. Moreover, the ubiquity of social media and its ability to break geographical barriers means that its use may blur the line between work and personal life. Stepping into any type of public forum also requires caution, such as in issues of confidentiality [27]. Also, ongoing concerns exist regarding social media use alignment to academic rigour as Barton \& Merolli 
(2019) argue, including: reputability of information, accuracy of content, privacy of individuals and professional obligations for use [4].

At the same time, there are challenges associated to using social media in academia, according to the study by Jaring \& Back (2017). The amount of information in social media and the task of following, as well as the speed and culture of social media pose challenges to researchers. Writing concise, smart, and interesting posts takes time, at least at the beginning. If using social media is part of the researcher's current project, being regularly active in social media is not a challenge, but without such a project, finding the time can be difficult. For instance, some of the top reasons why scientists are reluctant to use Twitter included a general lack of knowledge and a perceived lack of time (Twitter viewed as time consuming practice). Further linked themes emerged around the suggestion that Twitter lacks scientific content and is not a scientifically "rigorous enough media" to support professional scientific debate. [13]

Some studies, such as the one by Rowlands et al (2011) suggest that a lack of time, lack of clarity of the exact benefits of social media, and general uncertainty act as a barrier to social media use in the workplace [25]. Of note, time constraints is also cited as the biggest obstacle to outreach for scientists [1].

But one should be aware, as Cheek \& Øby (2019) duly note, that reluctance to engage with scholarly social media may cause a misrepresentation of a researcher's academic achievements and may come with unforeseen consequences. These include having a profile generated for oneself by search engines and other sites, and not knowing it, thereby not being aware of inaccuracies in aspects of one's "incidental" online researcher self being constructed and presented online automatically by search engines, such as Google Scholar. [6]

\section{Conclusions}

There is nothing new in researchers needing to profile themselves and their research, as scholarly reputation and discoverability of research have always been a top priority for scientists. They are constantly asked to profile their researcher selves and research outputs in CVs, job applications, and tenure applications, on institutional marketing sites, and in biographies that accompany research articles, chapters, or books they write [6]. What is new is the form and instant reach of a digitally based research profile, and the ways that the content of that profile is used to position researchers and their research in the contemporary research environment.

Building one's professional reputation seems to require active content creation and sharing both through social media and traditional media channels. Given that the amount of content in social media is huge and there is lot of competition for getting attention, gaining visibility and strengthening one's reputation requires active participation [13]. As Priem [21] urges - it is time to embrace the Web's power to disseminate and filter scholarship more broadly and meaningfully.

Most universities and research institutes use social media to some extent, but its true potential is unclear. Close collaboration between a research institute, its researchers, and industry is important also for the society, because the quicker the research results are commercialized, the bigger the benefits are to the companies and the society. Therefore, increasing understanding of how social media can be used efficiently is worth researching. 
Balancing the pros and cons, it is up to the individual scientists to decide upon using social media [27]. But once they decide to participate it is important to have a clear idea of what they would like to achieve from their online interactions, and to decide which platforms would best serve this purpose.

\section{References}

[1] ANDREWS, E., WEAVER, A., HANLEY, D., SHAMATHA, J. H. and MELTON, G., (2005) Scientists and public outreach: Participation, motivations, and impediments. J Geosci Ed. 2005; 53: $281-293$.

[2] Academia. (2018a). About Academia.edu. Retrieved from https://www.academia.edu/about

[3] BAR-ILAN, J. et al. (2012) Beyond citations: Scholars' visibility on the social Web. Available: https://arxiv.org/abs/1205.5611

[4] BARTON, C. J. and MEROLLI, M. A., (2019) It is time to replace publish or perish with get visible or vanish: opportunities where digital and social media can reshape knowledge translation. British Journal of Sports Medicine. 53:594-598.

[5] BOYD, D. M. and ELLISON, N. B., (2007). Social Network Sites: Definition, History, and Scholarship. Journal of Computer-Mediated Communication. Vol. 13, Issue 1, 210-230.

[6] CHEEK, J. and ØВY, E., (2019). "Getting Attention" Creating and Presenting the Visible, Online, Researcher Self. Qualitative Inquiry, 25(6), 571-582.

[7] COLLINS, K., SHIFFMAN, D. and ROCK, J., (2016) How Are Scientists Using Social Media in the Workplace? PLoS ONE 11(10): e0162680. https://doi.org/10.1371/journal.pone.0162680

[8] DESROCHERS, N., PAUL-HUS, A., HAUSTEIN, S., COSTAS, R., MONGEON, P., QUANHAASE, A. and LARIVIERE, V., (2018). Authorship, citations, acknowledgments and visibility in social media: Symbolic capital in the multifaceted reward system of science. Social Science Information, 57(2), 223-248.

[9] FRENCH, R. B. and FAGAN, J. C., (2019) The Visibility of Authority Records, Researcher Identifiers, Academic Social Networking Profiles, and Related Faculty Publications in Search Engine Results, Journal of Web Librarianship, 13:2, 156-197, DOI: 10.1080/19322909 .2019 .1591324

[10] G7 SCIENCE MINISTERS' COMMUNIQUÉ. [online] Turin, 27 - 28 September 2017. Available: http://www.g7italy.it/sites/default/files/documents/G7\%20Science\%20Communiqu $\%$ c3\%a9/index.pdf

[11] Google. (2018c). Inclusion guidelines for webmasters. Retrieved from https://scholar.google. com/intl/en/scholar/inclusion.html\#content

[12] HADDAD, F. S., (2017) How much evidence does it take to change practice? The Bone \& Joint Journal Vol. 99-B, nr. 7. https://doi.org/10.1302/0301-620X.99B7.BJJ-2017-0695 
[13] JARING, P. and BÄCK, A., (2017). How Researchers Use Social Media to Promote their Research and Network with Industry. Technology Innovation Management Review, 7(8): 3239. http://doi.org/10.22215/timreview/1098

[14] KAPLAN, A. M. and HAENLEIN, M., (2010). Users of the world, unite! The challenges and opportunities of Social Media. Business Horizons. Vol. 53, Issue 1, 59-68.

[15] MCCLAIN, C. and NEELEY, L., (2014). A critical evaluation of science outreach via social media: its role and impact on scientists. F1000Research, 3, 300. doi:10.12688/f1000research.5918.2

[16] MURRAY, A. D., MURRAY, I. R., BARTON, C. J., VODDEN, E. J. and HADDAD, F. S. (2018) Increasing research visibility to maximize impact. The Bone \& Joint Journal VOL. 100B, NO. 8. DOI: 10.1302/0301-620X.100B8.BJJ-2018-0683

[17] Mutual Learning Exercise: Open Science - Altmetrics and Rewards. Luxembourg: Publications Office of the European Union, 2018. ISBN 978-92-79-82004-5.

[18] NENTWICH, M. and KÖNIG, R., (2014) Academia Goes Facebook? The Potential of Social Network Sites in the Scholarly Realm. In: Bartling S., Friesike S. (eds) Opening Science. Springer, Cham.

[19] Open Innovation, Open Science, Open to the World - a vision for Europe. C European Union, 2015. ISBN 978-92-79-57345-3.

[20] ORCID. (2018b). What is ORCID. Retrieved from https://orcid.org/about

[21] PRIEM, J., Beyond the paper. Nature 495, 437-440 (2013). https://doi.org/10.1038/495437a

[22] PRIEM, J. and HEMMINGER, B. H., Scientometrics 2.0: New metrics of scholarly impact on the social Web. First Monday, [S.1.], July 2010. ISSN 13960466. Available at: https://firstmonday.org/ojs/index.php/fm/article/view/2874/2570

[23] Research Evaluation Metrics. [online] (C) UNESCO 2015. ISBN 978-92-3-100082-9. Available: https://unesdoc.unesco.org/ark:/48223/pf0000232210

[24] ResearchGate. (2018a). About. Retrieved https://www.researchgate.net/about

[25] ROWLANDS, I., NICHOLAS, D., RUSSELL, B., CANTY, N. and WATKINSON, A., (2011) Social media use in the research workflow. 10.3233/ISU-2011-0623

[26] SMITH, K., (2019). 126 Amazing Social Media Statistics and Facts [online]. Available: https://www.brandwatch.com/blog/amazing-social-media-statistics-and-facts/

[27] Social media for scientists. Nat Cell Biol 20, 1329 (2018). https://doi.org/10.1038/s41556-0180253-6

[28] Using social media [online]. (C) ESRC 2020. Available: https://esrc.ukri.org/research/impacttoolkit/social-media/using-social-media/ 
[29] VAN NOORDEN, R., (2014). Online collaboration: Scientists and the social network. Nature, 512(7513), 126-129. doi:10.1038/512126a 